\title{
Management Education in India Issues and Concerns
}

\author{
Shubhendu S. Shukla \\ Asst. Professor, SR Group Of Institutions, Lucknow, India \\ ssshubhendu@gmail.com
}

\begin{abstract}
The main objective of the present paper is to know the present scenario and historical development of management education in India \& to investigate its major issues \& concerns.

Today we need good and active managers for the development of country. Managers should know all the facts, logic and strategies. For this they should get education from good institutions. Today in India we have large no of management institutions but they are not giving education up to the mark. And also they demand high fee from students. Instead if we have average no of institutions providing good quality of managers then it would be beneficial for all students, companies and country also. Government should make some policies in this regard.

Owing to the globalization, privatization \& liberalization lot of changes are noticed in the functioning of industries. Naturally industries across the world are required to have the manpower with multi-skills rather than simply knowledge oriented. Western B-Schools are molding their self \& making the changes in their curricula as per the demand of industries. Now a day's learning has become more students centric. Branding has made in-roads into management education. Top B-Schools are continuously changing the contents \& delivery modes. It is equally imperative to Indian B-Schools to make management education context specific. On this back ground it is equally important to address the various issues \& concerns of Indian management education experiencing with time. Expectations from corporate executives decision makers and problem solvers have increased tremendously. Professional Education now needs to move beyond conventions in order to catch up with a rapidly changing context.
\end{abstract}

Keywords: All India council for technical education (AICTE), Association of Advanced Collegiate School of Business(AACSB), National Knowledge Commission(NKC), National Task Force(NTF), Management Education Entity(MEE), The Association of Management Institutes in Calicut University (AMICU), National Task Force (NTF), Xavier Labor Relations Institute (XLRI), The Associated Chambers of Commerce and Industry of India (ASSOCHAM) Proliferation

\section{Introduction}

Present corporate world is full of competition. New technologies are emerging every day and everything is turning towards globalization. In such challenging situation, young managers possessing management degree turn out to be survivors. The biggest challenge of the corporate world is to produce efficient managers.

A management degree from a reputed institution certifies that the person holding the degree has enough managerial skills required to face the competition. Management courses develops skillful workforce which constitutes of leaders of future as well as competitive 
managers. They have the ability to handle complex business situations. They maintain healthy relationships with clients.

\section{Evolution of Management Education}

Business education has a long history in India, dating back to the 19th century. Early Business-Schools were focused on the commercial side of business, seeking to fulfill the needs of the then British government.

- India's first B-school, i.e., Commercial School of Pacchiappa Charties was set up in 1886 in the southern city of Chennai (Madras).

- In 1903, British government initiated Secondary school level commerce classes at the Presidency College in Calcutta with a focus on Secretarial practice, Business Communication, Short hand, Typing, Correspondence \& Accounting.

- The first college level Business School was founded in 1913 in Mumbai i.e. Sydenham College.

- Soon followed by another college in Delhi in 1920 as Commerce College, later on it was renamed as Sri Rama College of Commerce.

- The Indian Institute of Social Science founded in the year 1948 as India's first management program with an intention to train manpower to create \& spread the knowledge required for managing industrial enterprises in India.

- Catholic community founded Xavier Labor Relations Institute (XLRI) at Jamshedpur in 1949.

- Indian Institute of Social Welfare \& Business Management (IISWBM) was set up in 1953 at Calcutta. That was considered as India's first official Management Institute.

- Encouraged by the results, Government of India applied for and obtained grant from the Ford foundation in 1961 to launch two (2) Indian Institutes of Management, one at Calcutta (West Bengal) and other at Ahmadabad (Gujarat). This grant was focused on helping American Business education knowledge \& models to other nations and having intensive collaboration with American B-Schools for facilitating the transfer of learning.

- The IIM Calcutta established in collaboration with the Sloan School of Management (MIT) for faculty \& pedagogy development in the year 1961, with an intention to focus on Quantitative \& Operational aspects of management.

- IIM Ahmadabad was founded in 1962, pioneered the case method of teaching in India with an emphasis on Qualitative strategic-integration.

- The mission of IIMs was to professionalize Indian Management education through teaching, research, training, institution-building \& consulting with the support of expertise developed by the pioneering IIMs.

- Two more IIMs were founded in Bangalore (Karnataka) \& other in Lucknow (U.P.) in 1973.

- The Indian Institute of Forest Management was setup in 1982 in Bhopal (M.P.) as a leader in specialized management education for the entire forestry system in India with the help of IIM, Ahmadabad. 
- In late 1990's, two more IIMs were setup, one at Kozhikode (Kerala) \& the other at Indore (M.P.).

- Growth both in numbers \& status occurred during the 1990's. A large number of multinational companies entered in India. Domestic companies also followed to compete with multinational corporations. Companies found that the graduates from commerce stream fell considerably short of the demands of the executive positions in a competitive world. They had good accounting skills but lacked requisite marketing, behavioral, finance \& operations skills. They were also weak in oral \& written communication, critical thinking \& critical reading skills and in Information technology. Consequently, rather incurring on training cost for commerce graduates companies started offering huge premiums for MBA graduates. Recognizing the success of MBA programs \& demands from students \& employer, universities started looking at management education as an academic discipline \& started offering MBA \& BBA programs.

\subsection{Overview of Management Education in India}

Today managers are in great demand in every sector of economy. India needs a huge reservoir each year of people who are trained for business and for management and demands is to last for coming years. But it is matter of concern whether the demand is for what they have been taught. In management education, quality has become a necessity. To make India an intellectual capital of the world, we have to create a dynamic environment, which can encourage superior quality management education colleges and effort should be made to breathe life into management education. Government has taken initiatives in this direction by giving node to 7 more IIMs taking the total number of the premier management school to 14 . India already has 11 functional IIMs in Ahmadabad, Bangalore, Kolkata, Lucknow, Indore, Kozhikode, Shillong, Tiruchirappalli, Ranchi, Raipur and Rohtak remaining three are to setup in state of $\mathrm{J} \& \mathrm{~K}$, Uttarakhand and Rajasthan. Apart from IIMs management education is offered by university's own department in campus, affiliated colleges of universities in same place or the whole State, now technical universities have been given this role.

Moreover autonomous institutes approved by AICTE, universities running distance education program and open mode like IGNOU, Delhi University, Kurukshetra University, ICFAI and several others are also offering courses in management. Some recognized institutes and universities are also offering 3 years part time program in evening faculty for working executives. Foreign universities having collaborations in India and those having students exchange program with limited-time studies abroad are also imparting management education. New private universities like ICFAI (a national brand), Amity and several others are now coming up.

According to annual report (2009-2010), published by Ministry of Human Resource Development, there were 20 Universities and 500 Colleges at the time of independence. At present, there are 504 Universities and university-level institutions (as on 31.12.2009) 243 State Universities, 53 State Private Universities, 40 Central Universities, 130 Deemed Universities, 33 institutions of national importance established under Acts of Parliament five Institutions established under various State legislations. There are 25,951 colleges of which, 7,362 are recognized under 2(f) and 5,997 colleges recognized under section 2(f) and declared fit to receive grants under section 12(B) of the UGC Act, 1956). Table 1 shown below shows growth of AICTE approved technical institutes in last five Years. In 2008-2009 the number institutes increased at exceptional rate, thus can be called the golden year in respect to establishment of institutes. In last 5 years the number of AICTE approved colleges has 
increased by almost $70 \%$ in total in various disciplines, whereas number of management institutes has seen growth of $90 \%$ in terms of number of institutes and growth of $123 \%$ in terms of intake as depicted in Table 2 in following figure.

Table 1. Growth of AICTE approved Technical Institutions in last five years

\begin{tabular}{|c|c|c|c|c|c|c|c|c|}
\hline Year & Engg & Mgmt & MCA & Phar & Arch & HMCT & Total & Added in Year \\
\hline $2005-06$ & 1475 & 1052 & 976 & 629 & 118 & 70 & 4320 & 383 \\
$2006-07$ & 1511 & 1132 & 1003 & 665 & 116 & 64 & 4491 & 171 \\
$2007-08$ & 1668 & 1149 & 1017 & 854 & 116 & 81 & 4885 & 394 \\
$2008-09$ & 2388 & 1523 & 1095 & 1021 & 116 & 87 & 6230 & 1345 \\
$2009-10$ & 2972 & 1940 & 1169 & 1081 & 106 & 93 & 7361 & 1131 \\
\hline
\end{tabular}

Source: www.aicte.ernet.in

Table 2. Growth of intake in AICTE approved Institutions in last five years

\begin{tabular}{|c|c|c|c|c|c|c|c|c|}
\hline Year & Engg & Mgmt & MCA & Pharm & Arch & HMCT & Total & Added in year \\
\hline $2005-06$ & 499697 & 80464 & 55548 & 32708 & 4379 & 4435 & 677231 & 40691 \\
$2006-07$ & 550986 & 94704 & 56805 & 39517 & 4543 & 4242 & 750797 & 73566 \\
$2007-08$ & 653290 & 121867 & 70513 & 52334 & 4543 & 5275 & 907822 & 157025 \\
$2008-09$ & 841018 & 149555 & 73995 & 64211 & 4543 & 5794 & 1139116 & 231294 \\
$2009-10$ & 1071896 & 179561 & 78293 & 68537 & 4133 & 6387 & 1408807 & 269691 \\
\hline
\end{tabular}

Source: www.aicte.ernet.in

There are $1800+$ B-Schools in the country. Since the dawn of the new millennium, a large number of universities \& colleges from not just the US \& UK but also from Australia, Ireland, Canada, Russia, France, Germany \& Singapore have been very active in India. The following Table 3 shows a growth of B-Schools in the country since last 55 years.

Table 3. Growth of B-Schools in India during 1950-2006

Sr. No. Period No. of B.Schools added Average Annual Addition

\begin{tabular}{rrrl}
1 & $1950-1980-30$ years & 118 & 04 \\
2 & $1980-1995-15$ years & 304 & 20 \\
3 & $1995-2000-05$ years & 322 & 64 \\
4 & $2000-2006-06$ years & 1017 & $169^{*}$ \\
\hline & 1761 &
\end{tabular}

Source: Dayal Ishwar, 'Developing Management Education in India', 'Journal of Management Research' 2 August 2006 P.101.2002. (The figures attributed for 2000-2006 as per AICTE data) ${ }^{2}$.

The early 1990's showed a boom of founding new management schools, most of them are in private sector. Few B-Schools have also being established in collaboration with some western universities. Management education in India is in the phase of change. The two current developments sweeping India, namely liberalization \& globalization have had a considerable impact on management education. Today there are 1800+ B- Schools in the country, spread over in different states of India, depicted in the following Table 4. 
Table 4. State-wise distribution of B-Schools in India

\begin{tabular}{llll} 
Sr. No. & \multicolumn{1}{c}{ State } & No. of B-Schools & $\%$ \\
01 & Andhra Pradesh & 239 & 13.5 \\
02 & Bihar & 14 & 0.8 \\
03 & Delhi & 60 & 3.4 \\
04 & Gujarat & 50 & 2.8 \\
05 & Hariyana & 34 & 1.9 \\
06 & Karnatka & 116 & 6.6 \\
07 & Kerala & 247 & 14.0 \\
08 & Madhya Pradesh & 51 & 2.9 \\
09 & Maharashtra & 202 & 11.5 \\
10 & Orissa & 247 & 14.0 \\
11 & Punjab & 25 & 1.4 \\
12 & Rajasthan & 56 & 3.2 \\
13 & Tamil Nadu & 139 & 7.9 \\
14 & Uttar Pradesh & 181 & 10.9 \\
15 & Uttarakhand & 18 & 1.0 \\
16 & West Bengal & 47 & 2.9 \\
17 & Others* & 35 & 1.9 \\
\hline \multicolumn{4}{c}{ Total } \\
$*$
\end{tabular}

\subsection{Some Facts}

- Current management models are losing their relevance. A decade ago, a management degree was the golden passport - a ticket to the job of your choice, but the Wall Street collapse has forced society to question the analytical approaches prevalent in today's business programs. The writing on the wall is 'innovate or die'. Where chief executives of the past were sensible and required to sell things proficiently, business leader today must touch lives and change paradigms.

- Merely $10 \%$ of graduates from business schools manage to get hired by corporate India.

- MBA seats annually in India have tripled from 4,500 to as many as 3.6 lakh.

- Campus recruitments have gone down by $40 \%$ in the same period.

- Only 5\% of undergraduate students in the country want a master's degree after graduation. Some students are time bounded as they already know what they want. Their priorities are to get a job at 22, get married by 24 and get on with the job of starting a family by 25 .

- About 2,00,000 students choose to go Abroad every year.

- Brain Drain in higher education is also one of the reasons to drop down enrollment rate for Management education in India.

- Lack of good placement is also one of the reasons that students are losing interest for higher education.

- In Europe, one year MBA degree has already become the dominant form of MBA training. 31 leading European business schools ranked among top 100 schools globally, over 22 schools offer degrees in 12 months, survey by Financial times and The Economist. 
- Study estimating that 180 schools had shut down in 2012 and another 160 schools offering MBAs were expected to close this year.

- The paper "B-Schools and engineering colleges shut down big business struggles" pointed to the lack of quality in faculty and the fact that most MBA courses were not adequately designed to match the industry's demands.

The Associated Chambers of Commerce and Industry of India (ASSOCHAM) paper on "B-schools and Engineering colleges shut down- Big Business Struggles" reveals that since 2009 , the recruitments at the campus have gone down by $40 \%$ in the year of 2012 as a result the B-schools and engineering colleges are not able to attract students, more than $180 \mathrm{~B}$ schools have already closed down in 2012 in the major cities Delhi-NCR, Mumbai, Bangalore, Ahmadabad, Kolkata, Luknow, Dehradun, etc. Another 160 are struggling for their survivals.

\section{Issues \& Concerns}

Though the number of committees on management education have suggested improvements. Still there have been no significant changes in management education except in the top ranking B-schools. Now the time has come to examine the major issues that need to be addressed if at all management education has to improve in India, So as the present managers can respond to the challenges of global Competition. In recent years business management has become one of the major higher studies in India. The reason for this is that a good knowledge about this field would change the economic background of an individual rather than the development of the country. Many high quality educational institutions are being set up in our country.

\subsection{Major Issues}

1. Ensure Quality Faculty.

2. Promote Research Culture.

3. Faculty Development Programs.

4. Develop reading materials relevant to Indian Context.

5. Develop interaction with Industry.

6. Evolve a proper system of Accreditation \& Rating.

7. Create an independent Institutional mechanism.

8. Corporate Governance of B-schools.

9. Need to broaden the specialization.

10. Create a global mindset.

11. Internationalize Management education.

\subsubsection{Ensure Quality Faculty}

Owing to the sanction of large number of B-Schools through AICTE resulted into shortages of qualified faculty. At present number of faculty members are without Ph.D. \& research background. In fact, at the University level UGC expects either Ph.D. or NET/SET as an essential qualification in the selection process at college or University level. But due to 
shortages of faculty in management only a master's degree is enough to become a faculty member in the B-schools. In selection process industry experience has given a special weightage but due to shortages of faculty, the industry experience is also not being judged properly in number of cases. Moreover AICTE has no machinery to develop \& train the faculty to teach management Courses with an applied basis. It is also observed that some of the institutions either engage partime faculty or appoint them on contractual basis where they have a little involvement either with the institution or with the students.

Newly joined faculty members adopt only lecture methods \& impart theoretical or conceptual knowledge to the students rather than brainstorming or its application.

New faculty members without any experience cannot take up the research or development of teaching materials \& deliver only the lectures mainly drawn from the text books.

\subsubsection{Promote Research Culture}

The management Institutions do not have culture that is supportive of research. Imbibing a research culture requires a good library support system. Scholars should be invited to undertake research in certain areas of national interest. Regarding the research grant procedure there is a need to support more to individual project proposals. Encourage to those institutes who have adequate support system to start Ph.D. program.

Being a recent development of management discipline there is a shortage of Ph.D. guides \& hence those who would like to persue for research degree they are forced to register for their $\mathrm{Ph}$.D. degree under the faculty of commerce. Many a times these Research guides in this field are unable to guide the candidates in the area of management.

\subsubsection{Faculty Development Programs}

In order to create good teachers for B-schools, the faculty development programs must be implemented on a large scale. Presently the teachers in the B Schools are prepared on a trial $\&$ error basis at the cost of present generation of students who are the real sufferers. Recently, AICTE had informed to management institutes to depute their faculty members to undergo Faculty Development Programs at the selected few centers but it is too inadequate. That will require another 5-10 years period to get the trained manpower with this system. Again the FDP programs which are implemented at the institutional level they are also not adequate \& rich in their Quality. As a part of formality \& conditions of the AICTE this activity is being implemented. In fact this scheme must be implemented at the regional levels throughout the country with the help of top ranking B-schools.

\subsubsection{Develop reading materials relevant to Indian Context}

It is observed that the ideas \& concepts which are effective in the countries of their origin but have been less effective in Indian context. So also the management practices adopted in Industrialized countries are in perfect harmony with their culture \& tradition, where as India has yet to do this exercise through systematic research \& study. The materials available are not yet-specific or relevant to Indian context. There are very few B-schools in India now they have started concentrating on research as well as preparing reading materials relevant to Indian context namely ICFAI, Hyderabad, MDI, Gurgaon, XLRI, Jamshedpur \& Wellingkar, Mumbai. 


\subsubsection{Develop interaction with Industry}

Except in case of top ranking B-schools, there are no mechanisms to forge close relationship between B-schools \& industry groups. The main strength of top class B-schools like Kellogg, Wharton, Sloan \& Howard is their strong relationship with industry through teaching, research, student placements, problem solving \& case study preparation. This issue in India is to make this happen in case of the low ranked B-schools in the country, there should be institutional mechanism for developing liaison with industry in each B-school.

\subsubsection{Need to evolve a proper system of Accreditation \& Rating}

In Indian management education it is one of the emerging issues is to identify the process to be adopted for implementation of an accreditation system. The accreditation has to be fair, transparent, independent as well as ruthless. The rapid growth in number of management institutes require a specialized body rather than the all encompassing AICTE to carry out accreditation. In fact a council, exclusively for management education is required \& the process of accreditation \& recognition need to be made separate. Recently the (NKC) National Knowledge Commission has recommended rating as an additional measure to inform the students, the parents \& the public of the Quality of Management education entity (MEE) because of mushrooming growth of schools in India. Many of which do not meet even the minimum requirements for the acceptable Quality. By requiring disclosure of information on rating a great service will be performed to all stake holders including students \& recruiters. Hence, the group has recommended that all MEE must have mandatory rating.

\subsubsection{Need to Create independent Institutional mechanism}

There are too many agencies deal with management education. Management education must be a concern of the body created by law for governing management education i.e. The All India Council for Technical Education \& its subsidiary. The Board of management studies combining the technical \& management education under one body was a mistake. A National Task Force (NTF) on Management education should be appointed. All India Management Association is of the opinion that there is a need of formation of All India Council for Management Education Quite independent of AICTE.

\subsubsection{Corporate Governance of B-schools}

As indicated by S.L. Rao, a major weakness is the lack of a Corporate Governance system in B-schools. This issue needs careful Consideration. There is a need to have independent Directors as well as to implement independent Audit Committee for managing the B-schools. The B-schools should become process driven. Corporate governance has to be made an element of accreditations. Faculty development as well as faculty involvement in the administration needs to be a part of the Corporate Governance agenda. Issues like Qualifications of faculty members, Size of libraries, \& other academic as well as infrastructural facilities must also become a part of governance.

\subsubsection{Need to broaden the specialization}

There are some businesses which are Context specific to India, e.g., agricultural services, infrastructure management, Contract research, hospital management \& NGO are rapidly growing areas in business. These businesses need customized management education. Curricula customization, Specific material development \& faculty specialization are some of the neglected factors that led to poor Quality of management education in India. No doubt 
some of the B-schools have introduced MBA, program, focused on telecom, financial services \& infrastructure management but still it requires more efforts on customization in order to broaden the Specialization.

\subsubsection{Create a global mindset}

This is a era of globalization. Industry needs executives with world-class talent. The issue is how to inculcate a global mindset through the managers who act locally. The survey Conducted by Andrews \& Tyson brought out some issues like.

In the changing economic scenario at global level the important issue is to create executives with management $\&$ leadership capabilities on a world wide scale. The study shows that there has been a shift in Companies while recruiting from knowledge to skills attributes.

Internationalization of business makes it necessary to have different knowledge \& sets. The notion is that business schools graduates must have cross cultural knowledge \& expertise which has steadily gained support \& become an important goal \& marker of achievement of many professional schools.

\subsubsection{Internationalize Management Education}

As the business is getting global, day by day there is an increasing need for the institutions (B-schools) to produce global Managers. Therefore, it has become necessary that the Indian Management education should also become more global. The response to globalization of business is the globalization of Management education.

Hence,

- The business schools must admit international students to the program. The Indian management institutes are the only ones with no international participation.

- The B-schools should induct a few international faculties \& provide an opportunity to the students to listen about other country's business culture $\&$ systems.

- The B-schools should provide an active program of students \& faculty exchange with advanced countries.

- To ensure that at least $25 \%$ of the curriculum deals with international subjects like international economics, International Marketing, International Financial Management or international Business Management, etc.

- Indian B-schools should collaborate with some well known foreign B-schools by which Indian students can do part of their education in those institutes.

- Lastly the B-schools also collaborate with some foreign placement Consultancies to make sure at least some students can obtain jobs abroad.

\section{Skills Required in Future Global Management}

- Against this backdrop, our future global manager would require the following new skills

- Information management skill

- Information technology management skill,

- Decision-making in very dynamic environment 
- HRD Skill

- Innovation/Creativity

- Service Sector management Skills,

- Time Management Skills

- Stress Management Skills

- Environment management Skills

- Entrepreneurship

- Customers Services Management Skills and

- Management schools will have to develop these skills among students.

Management institutes will have to introduce new Service Sector Management Course, like travel and Tourism Management, Hospital Management, Consultancy Management, NGO Management, Advertising Management, Banking and Insurance Services Management, Farm Management, etc.

Needless to say, courses should be need based and syllabi should be changed periodically. Lack of specialization specific to industry, is one to the problems of our MBA program.

\section{Conclusion}

- Aside from the top 20 business schools like the Indian Institutes of Management (IIMs), merely $10 \%$ of graduates from business schools manage to get hired by corporate India. In the last five years, the number of MBA seats annually in India has tripled from 4,500 to as many as 3.6 lakh, according to an ASSOCHAM study, but campus recruitments have gone down by $40 \%$ in the same period.

- Indian management institutes should internationalize their approach to equip students to become global managers. At the same time, Indian business schools should take care to ensure that their courses had enough local content so that students could relate to them easily.

- Change in study material and teaching methodology with time as it is said "Any corporate which does not change with time is bound to die,".

- Experts opine that old curriculum and teaching methodologies in B-schools has not able to keep pace with fluid and dynamic environment.

- Encouraging a series of private quality institutions and institutions with public private partnership completely deregulating higher education. This will open wider options for students to enroll them in Good B-school.

\section{References}

[1] A. Conger and R. M. Fulmer, "Developing your leadership pipeline", Harvard Business Review, (2003) December.

[2] AACSB International, "The value proposition for Business Education", CIME Task force report; Ethics Education in Business Schools, (2004).

[3] AICTE Hand Book year 2006-07, (2006).

[4] A. K. Penthoi and S. Dash, "Indian Higher Education in the Era of Globalization: Challenges \& Quality management strategies", University News, (2005) December. 
[5] Bowonder and S. L. Rao, "Management education in India its evolution \& some contemporary issues", AIMA/CME 2005, (2005).

[6] D. Ishwar, "Developing Management Education in India", Journal of Management Research, (2006) August 2, pp. 101.

[7] F. C. Pierson, "The Education of American Businessmen”, McGraw Hill, New York, (1959).

[8] GFM, The Global Management Education Landscape, Shaping the future of Business Schools, (2007).

[9] J. Storey and K. Sisson, "Making Managers in Britain", Public Money and Management, (1990).

[10] G. G. Saha, "Management Education in India: Issues \& Concerns", Journal of Information, Knowledge and Research in Business Management and Administration, ISSN: 0975 - 671x| nov 11 to oct 12 |, vol. 2, issue 1.

[11] http://articles.timesofindia.indiatimes.com/keyword/management-education.

[12] http://www.indiabix.com/group-discussion/management-education-in-india/.

[13] The Times Of India (Edition New Delhi - January 31 2013), (2013).

[14] http://education.oneindia.in/news/2013/04/26/revising-the-trend-in-management-education-in-india004768.html.

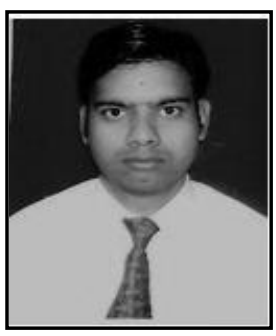

Author (Shubhendu S. Shukla), has completed his MA (Economics) in 2005 and MBA in 2007, and M.Phil (Management) in 2010. He has done Post Graduated Diploma in Computer Applications from IGNOU and Post Graduated Diploma in International Business from Annamalai University.

Author is Member of Editorial Board in Reviewer Panel of International Journal of Science and Research (IJSR) ISSN: 2319-7064 (www.ijsr.net/editorial.php), International Journal of Scientific Engineering and Research (IJSER) (www.ijser.in/members.php), International Journal of Engineering Research and Technology (IJERT) ISSN: 2278-0181, ISO 3297:2007 http://www.ijert.org/about-us/reviewboard?start=9), International Journal of Modern Communication Technologies \& Research (IJMCTR), Engineering Research Publication ISSN :2321-0850, An ISO 9001:2008 certified online journal http://erpublication.org/IJMCTR/Editorial\%20Board.htm).

He has worked with a prominent IT Company (Wipro Technologies) as Project Manager for e-Governance that was a Central Govt. Project about e-District, during his job he was responsible for Dealing with Consultant (Wipro), dealing with Techo team i.e. Trainer and other staff, he also Co-ordinate with District Administrative staff for monitoring, reporting, and his proposals and finally developed the Study materials.

Author has more than 5 years of experience in academics as he is currently working as Asst professor in SR Group of Institutions, Lucknow. With the academics author has publish 9 International Research Paper, 5 national Research Papers, attended 7 National Conferences and Seminars, 4 International Seminars. Apart from SR Group of Institutions, Lucknow, he is Guest and Visiting Faculty of Study Centers of Global Open University Nagaland, Karnataka State Open University, Sikkim Manipal University. 
International Journal of Education and Learning

Vol. 2, No. 2 (2013)

Author has taught variety of subjects as Marketing, Sales and Distribution, Production and Operation management, Computer Application in Management, System Analysis \& Design and Software Engineering, Database Management System, Electronic Commerce (Specialized subjects of Information Technology). 